\title{
Envelhecimento e doença de Alzheimer: reflexões sobre autonomia e o desafio do cuidado
}

Claudia Burlá ${ }^{1}$, Leo Pessini ${ }^{2}$, José Eduardo Siqueira ${ }^{3}$, Rui Nunes $^{4}$

\section{Resumo}

Este trabalho propõe uma reflexão sobre a perda da autonomia, com a consequente dependência total do outro, na desafiante relação de cuidado com a pessoa idosa afetada pela doença de Alzheimer. Desde seus primórdios a bioética provoca reflexões sobre questões complexas e instigantes originadas no avanço da tecnociência. $\mathrm{Na}$ área da saúde, a demografia e a epidemiologia demonstram o aumento crescente de idosos devido ao acelerado progresso biotecnológico e às melhores condições de vida. Entretanto, há evidências de que o envelhecimento torna o organismo mais suscetível a doenças e à vulnerabilidade ao acometimento pela doença de Alzheimer. Neste cenário, persiste a indagação sobre as possibilidades da relação de cuidado ético voltada à reconstrução da autonomia da pessoa idosa que a perdeu nos meandros da doença de Alzheimer. A ausência de respostas desafia a geriatria e a gerontologia a buscarem orientação com base nos referenciais da bioética. Palavras-chave: Envelhecimento. Autonomia pessoal. Doença de Alzheimer. Bioética.

\section{Resumen}

El envejecimiento y la enfermedad de Alzheimer: reflexiones sobre la pérdida de la autonomía y el desafío la atención

Este artículo propone una reflexión sobre la pérdida de autonomía y, como consecuencia, la dependencia total de otros, en la desafiadora relación de cuidado con la persona mayor afectada por la enfermedad de Alzheimer. Desde los albores de su historia, la bioética provoca reflexiones sobre cuestiones complejas e instigadoras que surgen con en el avance de la tecnociencia. En materia de salud, la demografía y la epidemiología demuestran el creciente número de personas de edad avanzada debido al rápido progreso biotecnológico y mejores condiciones de vida. Sin embargo, hay evidencias de que el envejecimiento hace que el cuerpo sea más susceptible a las enfermedades, y más vulnerable a la aparición de la enfermedad de Alzheimer. En este escenario, se investiga las posibilidades de la relación de cuidado ético centrado en la reconstrucción de la autonomía de la persona mayor que se perdió en el curso de la enfermedad de Alzheimer. La ausencia de respuestas es un desafío a la geriatría y gerontología para la búsqueda de orientación con base en referenciales bioéticos. Palabras-clave: Envejecimiento. Autonomía personal. La enfermedad de Alzheimer. Bioética.

\section{Abstract}

\section{Aging and Alzheimer's Disease: reflections on the loss of autonomy and the challenges of care}

This paper fosters a reflection on the loss of autonomy and the ensuing total dependence on the Other in the challenging care-provision interaction with the individual affected by Alzheimer's disease. Since its inception, Bioethics instigates reflections on complex and intriguing issues stemmed from techno-science advancements. In health-related areas, demography and epidemiology indicate a growing increase of older persons, due to accelerated bio-technological developments and better living conditions. There are evidences, however, that aging makes the body prone to the development of diseases, and more vulnerable to Alzheimer's disease. In this scenario, one should ponder on the possibilities of an ethical care aiming to reconstruct the autonomy of the older person that was lost in the tangles of Alzheimer's disease. The lack of responses challenges Geriatrics and Gerontology to seek guidance from the referentials of Bioethics.

Key words: Aging. Personal autonomy. Alzheimer's disease. Bioethics.

1. Doutoranda claudia@burla.com.br - Faculdade de Medicina da Universidade do Porto, Portugal 2. Doutor pessini@saocamilo-sp. br - Centro Universitário São Camilo, São Paulo/SP, Brasil 3. Doutor - jtsique@sercomtel.com.br Universidade Estadual de Londrina, Londrina/PR, Brasil 4. Doutor ruinunes@med.up.pt - Faculdade de Medicina da Universidade do Porto, Portugal.

Cláudia Burlá - Rua Artur Araripe 43, apt ${ }^{\circ}$ 1.003, Gávea CEP 22451-020. Rio de Janeiro/RJ, Brasil. 
Com a expansão do conhecimento proporcionado pela tecnociência, que influencia todos os âmbitos da vida, as realidades sempre mais complexas e polêmicas exigem discernimento ético para que se possa optar por alternativas que não firam a dignidade do ser humano. Notadamente na área do envelhecimento, o processo de aquisição de conhecimento vem proporcionando à humanidade a ampliação constante da perspectiva de alcançar qualidade de vida e felicidade de viver. Desde o início da década de 70, a bioética tem presença obrigatória na pauta dessas reflexões e discussões sobre valores humanos que se articulam ao empreendimento técnico-científico, que intervém no âmbito da vida em geral e na existência humana em particular.

O crescimento da literatura bioética revela a sua aplicação em diversas áreas do conhecimento, bem como em práticas de saúde nas quais despontam grandes problemas da atualidade. O fenômeno do envelhecimento é exemplo dessa situação que cresce contínua e exponencialmente, trazendo consequências diretas a todos os níveis da organização humana, do individual-familiar ao político-econômico.

Este artigo traz um histórico do surgimento da bioética, tentando alcançar a sua abrangência maior, com destaque para a área da saúde. Afinando o foco, abordamos os desafios relacionados aos cuidados aos idosos portadores da doença de Alzheimer, utilizando para isso, especialmente, o referencial bioético da autonomia. Ainda que não pretenda um levantamento sistemático nem da literatura bioética nem daquelas oriundas das áreas da geriatria e da gerontologia, é importante citar que embasam a argumentação do presente artigo textos considerados indispensáveis para que seja assumido, com consistência técnica e sensibilidade ética, o desafio de refletir sobre o cuidado a uma pessoa com a perda da autonomia nesta fase da vida.

\section{Ponto de partida: ponte entre ciência e ética}

Nos anos 1970-71, o bioquímico norte-americano Van Rensselaer Potter cunhou o neologismo bioethics, utilizando-o em duas publicações: o artigo Bioethics, science of survival ${ }^{1}$ e o livro Bioethics: bridge to the future ${ }^{2}$. Potter, que nestes trabalhos iniciais chama a bioética de ciência da sobrevivência humana, traça uma agenda de trabalho que vai desde a intuição da criação do neologismo, ainda em 1970, até a possibilidade de encarar a bioética como disciplina sistêmica ou profunda, já em 1988.
Segundo o autor, essa nova ciência combina o trabalho de humanistas e cientistas cujos objetivos são sabedoria e conhecimento. A sabedoria é definida como o saber sobre o modo de usar o conhecimento para o bem social. A busca da sabedoria tem nova orientação porque a sobrevivência humana está em jogo. Nesse contexto, os valores éticos devem ser testados em termos de futuro e não podem ser dissociados dos fatos biológicos ${ }^{3}$.

Assim, Potter pensa a bioética como ponte entre a ciência biológica e a ética. Almeja criar nova disciplina com verdadeira dinâmica e interação entre o ser humano e o meio ambiente. Persegue a intuição de Aldo Leopold e, nesse sentido, se antecipa ao que hoje se tornou preocupação mundial: a ecologia. Sua intuição consiste em pensar que a sobrevivência da espécie humana, numa civilização decente e sustentável, depende do desenvolvimento e da manutenção de um sistema ético: Se existem duas culturas que parecem incapazes de dialogaras ciências e humanidades - e se isso se apresenta como uma razão pela qual o futuro se vislumbra duvidoso, então, possivelmente, poderíamos estabelecer condições de passagem para o futuro, construindo a bioética como uma ponte entre as duas culturas. No termo bioética (do grego bios, vida e ethos, ética) bios representa o conhecimento biológico, a ciência dos sistemas vivos, e ética representa o conhecimento dos valores humanos ${ }^{2}$.

Um outro pioneiro na bioética é o obstetra holandês André Hellegers, da Universidade de Georgetown, em Washington, que seis meses após a aparição do livro de Potter - Bioethics: bridge to the future - utilizou a expressão no nome do novo centro de estudos: Joseph and Rose Kennedy Institute for the Study of Human Reproduction and Bioethics. Hoje, este centro é internacionalmente conhecido como The Kennedy Institute of Ethics.

Hellegers animou um grupo de discussão de médicos e teólogos (protestantes e católicos) que viam com preocupação crítica o progresso médico tecnológico que apresentava enormes e intrincados desafios aos sistemas éticos do mundo ocidental. Para Reich, historiador da bioética e editor-chefe das duas primeiras edições da Encyclopedia of bioethics (1978 e 1995), o legado de Hellegers está no fato de entender que sua missão em relação à bioética seria a de ser pessoa-ponte entre a medicina, a filosofia e a ética. Esse legado, que acaba sendo hegemônico ao longo do tempo, associa a bioética à ética biomédica ${ }^{4-6}$.

Portanto, desde o momento do seu nascimento a bioética tem dupla paternidade e duplo enfo- 
que. Pode-se dizer que se apresentam problemas de macrobioética (meio ambiente, ecologia), com inspiração na perspectiva potteriana, e problemas de microbioética (bioética clínica), com clara inspiração em Hellegers.

Embora reconheça a importância da perspectiva de Georgetown, Potter afirma que a bioética contempla abordagem bem mais ampla. Pretende que seja uma combinação de conhecimento científico e filosófico, o qual, em 1988, chama de global bioethics - que não seria simplesmente um ramo da ética aplicada, como a bioética foi entendida em relação à medicina ${ }^{7,8}$.

Potter amplia o conceito de bioética em relação a outras disciplinas, fazendo desta não somente ponte entre a biologia e a ética, mas uma ponte para uma ética global: Tal sistema (a implementação da bioética ponte) é a bioética global, fundamentada em intuições e reflexões referenciadas no conhecimento empírico proveniente de todas as ciências, porém, em especial, no conhecimento biológico. $\mathrm{Na}$ atualidade este sistema ético proposto segue como o núcleo da bioética ponte, com sua extensão para a bioética global, uma vez que a função de 'ponte' exigiu o encontro da ética médica com a ética do meio ambiente, numa escala mundial para preservar a sobrevivência humana ${ }^{8}$.

O autor expõe a ideia da bioética profunda, aludindo os avanços da biologia evolutiva, em especial o pensamento sistêmico e complexo que comporta os sistemas biológicos. A bioética profunda, por sua vez, entende o planeta como grandes sistemas biológicos entrelaçados e interdependentes, em que o centro já não corresponde ao homem, como em épocas anteriores, mas à própria vida. A respeito, considera:

À medida que chego ao ocaso de minha experiência, sinto que a Bioética Ponte, a Bioética Profunda e a Bioética Global alcançaram um umbral de um novo dia que foi muito além daquilo que eu imaginei. Sem dúvida, necessitamos recordar a mensagem do ano de 1975 que enfatiza a humildade com responsabilidade, como uma Bioética básica que, logicamente, segue uma aceitação de que os fatos probabilísticos, ou em parte a sorte, têm consequências nos seres humanos e nos sistemas viventes. A humildade é a consequência característica que assume o 'posso estar equivocado' e exige a responsabilidade para aprender da experiência e do conhecimento disponível. Concluindo, o que lhes peço é que pensem a Bioética como uma nova ética científica que combina a humildade, responsabilidade e competência numa perspectiva interdisciplinar e intercultural e que potencializa o sentido de humanidade ${ }^{9}$.

Esta conclusão de Potter é inspiração para este trabalho ao refletir sobre o desafio dos profissionais da área do envelhecimento frente a uma pessoa idosa que vê a sua autonomia desaparecendo no curso da doença de Alzheimer.

\section{Bioética ao encontro da geriatria e gerontologia}

Em busca de compreensão sobre o que se entende por bioética é imperioso consultar uma das obras referenciais desse novo campo do saber, a Encyclopedia of bioethics. Essa obra foi publicada nos Estados Unidos da América em três diferentes edições, completamente revistas e atualizadas, em momentos distintos de evolução histórica da bioética: $1^{\text {a }}$ edição em 1978; 2a , em 1995 e 3a , em $2003^{4,5,9}$. As duas primeiras tiveram como editor-chefe Warren Thomas Reich, da Georgetown University, e a terceira Stephen G. Post. Vejamos como a bioética foi definida nessas três edições ${ }^{3}$.

Em sua primeira edição a bioética era ainda nova e relativamente indefinida. Desse modo, foi entendida como o estudo sistemático da conduta humana no âmbito das ciências da vida e da saúde, examinada à luz de valores e princípios morais. Assim, a bioética abarca a ética médica, porém não se limita a ela. Em seu sentido tradicional, a ética médica trata dos problemas relacionados com valores, que surgem da relação médico-paciente. A bioética constitui um conceito mais amplo, com quatro aspectos importantes ${ }^{4}$ :

- engloba os problemas relacionados aos valores que surgem em todas as profissões de saúde, inclusive nas profissões afins e naquelas vinculadas à saúde mental;

- aplica-se às pesquisas biomédicas e às do comportamento, independentemente de influírem ou não de forma direta na terapêutica;

- aborda ampla gama de questões sociais, as quais se relacionam com a saúde ocupacional e internacional e com a ética do controle de natalidade, dentre outras;

- vai além da vida e da saúde humanas, enquanto compreende questões relacionadas à vida dos animais e das plantas, englobando as questões éticas relacionadas com pesquisas em animais, bem como aos desafios éticos ligados com o meio ambiente. 
Embora essa edição pioneira de 1978 seja fascinante de ler e estudar, para entendermos a evolução histórica do conceito de bioética, com a rápida evolução técnico-científica no âmbito das ciências da vida e da saúde, no decorrer da década seguinte nova versão se fez necessária. Surgiu, então, uma edição revisada, publicada em 1995 por Macmillan Reference Division, em cinco volumes. Aprofunda, entre outras questões, a história da ética médica e o movimento de crescimento da bioética, contemplando a reflexão de pensadores europeus para além dos norte-americanos, que apresentam suas reflexões em questões de ética religiosa, filosofia moral e ética clínica no exercício da medicina científica ${ }^{5}$.

Esse novo campo do saber revela a bioética, neologismo derivado das palavras gregas bios (vida) e ethikós (ética), que pode ser definida como o estudo sistemático das dimensões morais das ciências da vida e da saúde, utilizando uma variedade de metodologias éticas, em um contexto interdisciplinar.

$\mathrm{Na}$ segunda edição foram incluídas novas questões, dentre outras: relação profissionalpaciente; bioética e ciências sociais; cuidados em saúde, fertilidade de reprodução humana, pesquisa biomédica e comportamental; história da ética médica, saúde mental e questões comportamentais; sexualidade e gênero; sobre a morte e o morrer; genética, ética da população; doação e transplante de órgãos, bem-estar e pesquisas com os animais; meio ambiente; códigos e juramentos de diversas profissões do âmbito dos cuidados de saúde e outras numerosas diretrizes éticas de organismos nacionais e internacionais ${ }^{5}$.

Após uma trajetória de pouco mais de três décadas, a bioética já tem um reconhecimento importante nas áreas científica e pública. No decorrer dos anos 90, a Encyclopedia of bioethics novamente passou por completa revisão e atualização. Reich, editor-chefe das duas versões, indicou como seu substituto Stephen G. Post, ligado ao Department of Bioethics, Medical School da Case Western Reserve University, de Ohio. De acordo com Post ${ }^{10}$, a definição de bioética da segunda edição revisada (1995) - como ficou sendo chamada - constitui-se no exame moral interdisciplinar e ético das dimensões da conduta humana, nas áreas das ciências da vida e da saúde, utilizando uma variedade de metodologias éticas num contexto interdisciplinar.

Na terceira edição, em 2003, é incluída ampla gama de novos assuntos que vão desde o bioterrorismo, holocausto, imigração, questões éticas de saúde humana, nutrição e hidratação artificiais, questões éticas relacionadas com diagnóstico e tra- tamento em oncologia até questões éticas ligadas à demência, diálise renal e ordens para não reanimar. Além disso, é apresentada uma série de artigos sobre clonagem e pediatria. Tópicos como reprodução e fertilidade, transplantes de órgãos e tecidos, sobre a morte e o morrer, teoria ética, bioética e políticas públicas (legislação), saúde mental, genética, religião e ética foram completamente revistos e são, na essência, novos ${ }^{10}$.

A área da geriatria e da gerontologia está amplamente contemplada no verbete Aging and the aged $^{10}$ :

\section{Teorias do envelhecimento e extensão da vida;}

II. Expectativa de vida e ciclo vital;

III. Envelhecimento societário;

IV. Questões ligadas aos cuidados de saúde e pesquisa;

V. Idosos;

VI. Intervenções antienvelhecimento: questões éticas e sociais.

Particularmente instigante e interessante em termos de futuro, e que vai exigir muita discussão ética, é a biogerontologia, ou seja, o estudo da biologia dos processos de envelhecimento humano. Chamamos a atenção para a importância do assunto em termos do impacto no futuro da vida humana e que interessa diretamente aos estudiosos de geriatria e gerontologia $\mathrm{A}$ questão do adoecimento dos idosos pela doença de Alzheimer é, dentre outras, uma preocupação bioética central no mundo atual, exigindo competências e protagonismos específicos. Essa enfermidade, a mais prevalente das demências, é de alto impacto individual, familiar e social pela radical perda progressiva e irreversível da autonomia da pessoa afetada ${ }^{11}$.

O debate apenas está começando e torna necessária uma reflexão bioética em meio à ousadia científica que se desvincula dos mistérios da carência do cuidado.

\section{Envelhecimento e velhice}

\section{Percurso de triunfo e dissabor}

Envelhecer é um processo natural do crescimento do ser humano, que se inicia com o nascimento e termina com a morte ${ }^{12}$. Consequentemente, uma filosofia do envelhecer deve começar com uma filosofia do ser humano. Cada ser humano é uma pessoa única, desde o primeiro momento da vida. A vida de crescimento e experiência forma 
um todo, único, personalizado e que não se repete. Viver não é simplesmente existir, mas desfrutar de qualidade de vida, desenvolvendo as potencialidades inerentes ao ser.

Embora o ser humano não escolha a hora de nascer ou morrer, esses dois momentos fundamentais - nascimento e morte - dão sentido ao seu viver e exigem cuidados especiais. O ser humano é um todo, uno, integrado e organizado. Todos os seus sentidos, emoções e órgãos do corpo estão intimamente inter-relacionados. Com a idade, mudanças na aparência e comportamento acontecem, mas não devem comprometer o valor da pessoa humana. A preocupação e o cuidado com os idosos não são diferentes da preocupação e cuidado correspondentes pela vida. Nossa filosofia de vida afeta diretamente os pensamentos, comportamentos e atitudes em relação ao idoso ${ }^{3}$.

O avanço na idade como dado isolado não é sinônimo de adoecimento nem de chegada da morte. Doença e morte são condições próprias dos seres humanos, em qualquer idade. Entretanto, existem evidências de que o envelhecimento humano torna o organismo mais suscetível a doenças. Concretamente, dados epidemiológicos expressivos demonstram a vulnerabilidade das pessoas que, cada vez mais veIhas, estão expostas à doença de Alzheimer ${ }^{13}$.

A rigor, uma filosofia da velhice deve levar em conta as perdas decorrentes do processo do enveIhecimento, não apenas o esperado na sua fisiologia, mas, especialmente, a ocorrência do dano físico que lesa, limita e acaba por conduzir o idoso à dependência total do outro. A doença, a antecipação da morte, os mitos e preconceitos de que os idosos são vítimas, bem como as riquezas e potencialidades de que são portadores, devem estar na pauta de gestores e assistentes em saúde. Lembremos que à medida que as pessoas envelhecem, suas perspectivas de vida diminuem proporcionalmente. Com frequência, não se orientam mais pelo futuro, mas contam seus dias a partir daqueles vividos - e nesse momento alguém deve estar lá, testemunhando a sua história ${ }^{3}$.

A compreensão do sentido do ser idoso deve ser colocada em perspectiva histórica e temporal: o processo de acumular anos, do qual o idoso é uma parte e expressão concreta do tempo. Afinal, ser gente é estar situado no tempo. Fundamentandose em Elliot Jacques ${ }^{14}$, Torres ${ }^{15}$ lembra que nessa última etapa da vida humana também há um fator do desenvolvimento. Para mudanças nessa fase, o decisivo é a consciência da proximidade da morte pessoal e, consequentemente, a ausência da perspectiva de futuro.
Do ponto de vista fenomenológico, a experiência de envelhecer atua como pressão do passado que cresce, enquanto diminui a possibilidade de futuro. O medo da velhice é detectado como o medo da morte, expresso, portanto, em receio e repulsa da velhice e da morte. Vale lembrar que a velhice, embora suscite possibilidades de saúde e produção, carreia também a vulnerabilidade do corpo que sofre perdas contínuas e progressivas, adoece crônica e incuravelmente, carecendo encontrar um sentido para o declínio, a dependência, a aproximação da morte inevitável.

É curioso o fato de as pessoas idosas sempre terem sido reconhecidas pela sociedade por avaliações ambíguas. Em princípio, por terem vivido muito, teriam a possibilidade de contribuir com experiência e sabedoria para aperfeiçoar a construção da comunidade onde estão inseridos. Esta é a percepção de Cícero em De senectute, obra em que considera a velhice como a presença do passado no presente, o que qualificaria os idosos como colaboradores competentes para tornar mais harmônica a vida em sociedade ${ }^{16}$.

A modernidade, entretanto, tornou o passado território de pouco valor. Sob o influxo dos frequentes avanços tecnológicos da modernidade o 'novo' ganhou status especial, solapando a reverência e o respeito tradicionalmente conferidos à sabedoria acumulada pelas pessoas idosas em todas as sociedades. Nessas condições, os idosos perdem prestígio nas relações pessoais e, nas relações institucionais, somente serão merecedores de respeito se não se transformarem em peso demasiado oneroso para o equilíbrio financeiro da gestão pública dos recursos destinados à área social - especialmente os investidos em saúde. O envelhecimento da população mundial é, portanto, seguramente o fator que mais deve preocupar as autoridades públicas neste século ${ }^{3,17}$.

Não é novidade a manipulação do imaginário social que recorre a campanhas para promover o rejuvenescimento dos velhos. Incentivam-se os idosos a assumir a condição de jovens, não somente na aparência física, mas também na assimilação de novos costumes. Para serem acolhidos pela sociedade de consumo, os idosos precisam renunciar a seus princípios morais e são coagidos a incorporar hábitos incompatíveis com seus valores pessoais.

O ser humano não é vítima da velhice; enveIhecer não é uma experiência passiva, ao contrário, requer ressignificação e integração como os outros estágios da vida, a adolescência, a juventude ou a idade adulta. A velhice terá um sentido no fim somente se a vida tiver um sentido no seu todo. 0 
inevitável é que, nos últimos anos, se acentuam as perdas, há uma diminuição das capacidades. Deve ser buscado novo sentido de vida que sustente tal experiência. Frequentemente, entende-se a velhice como direcionada para a morte, mas não se deve esquecer que ela é também direcionada para o crescimento. Muitos, só na velhice conseguem ver a vida como um todo ${ }^{18,19}$.

O ser humano, "o grande desconhecido" de Carrel, é, na verdade, extremamente complexo ${ }^{3}$. $\mathrm{Na}$ velhice, a peculiaridade do caráter crônico, progressivo e irreversível das doenças - como, por exemplo, a doença de Alzheimer - confronta familiares do idoso e profissionais que dele cuidam em desafiadora demanda de cuidados para alguém que vai se afastando de si mesmo, tornando-se efetivamente desconhecido. Toda pessoa doente, na visão de Michel Foucault, sempre expressará a doença com traços singulares, com sombra e relevo, modulações, matizes e profundidade, sendo que a tarefa do médico ao descrever a enfermidade será a de reconhecer esta realidade viva ${ }^{20}$.

Ao subestimarmos os valores biográficos do idoso com demência e percebê-lo como um árido conjunto de variáveis biológicas, nos transformamos em profissionais que tratam de uma doença que, mais do que tratamento, requer cuidados ao paciente, estendidos aos seus familiares. A relação profissional-paciente-familiares jamais deixará de ser um encontro intersubjetivo vivenciado por todas as pessoas envolvidas. Contudo, por mais assimétrica seja, somente será adequada se conduzida com acolhimento, escuta ativa e esperança de alívio e conforto para os que sofrem. Como previra Hellegers no início dos anos 70 , nossos problemas biomédicos no alvorecer do século XXI são mais éticos do que técni$\cos ^{7}$. A atualidade do aumento do envelhecimento no mundo, conquista admirável da civilização, traz intrínseco o desafio da presença crescente de idosos incapacitados que incitam a uma mudança radical nas relações humanas que, agora, precisam incluir na sua dinâmica a ética do cuidado.

\section{Doença de Alzheimer}

\section{Apelo à autonomia}

Para adentrarmos na área da doença de Alzheimer, invocamos Viktor Frankl: Precisamos manter um 'otimismo trágico' sobre os dementados - a necessidade de acreditar que existe um espírito que continua a brilhar nas suas almas quando todo o resto parece perdido para sempre ${ }^{21}$. A demência é uma síndrome devida à doença cerebral, habitualmente de natureza crônica e progressiva, em que há comprometimento de funções corticais, incluindo memória, raciocínio, orientação, compreensão, cálculo, capacidade de aprendizagem, linguagem e julgamento ${ }^{22}$.

De acordo com o relatório de 2012 da Organização Mundial da Saúde (OMS), atualmente mais de 35 milhões de pessoas em todo o mundo têm demência, número que deverá duplicar em 2030 (66 milhões) e triplicar até 2050 (115 milhões). A doença de Alzheimer é a forma mais comum de demência, respondendo por $60 \%$ a $70 \%$ dos casos, não tem cura e não existem tratamentos aprovados que impeçam a progressão dos sintomas ${ }^{23}$. 0 grupo de trabalho do National Institute on Aging e da Alzheimer's Association, durante reuniões em 2009, elaborou novas recomendações para o diagnóstico clínico da doença de Alzheimer, apresentadas na International Conference on Alzheimer's Disease, em 2010 24-27.

A demência é diagnosticada quando há sintomas cognitivos ou comportamentais que interferem com a habilidade no trabalho ou nas atividades básicas da vida diária e que necessariamente representam declínio em relação a níveis prévios de funcionamento e desempenho. Os comprometimentos cognitivos ou comportamentais afetam, no mínimo, dois dos seguintes domínios:

- memória, caracterizado por comprometimento da capacidade para adquirir ou evocar informações recentes, com sintomas que incluem: repetição das mesmas perguntas ou assuntos, esquecimento de eventos, compromissos ou do lugar onde guardou seus pertences;

- funções executivas, caracterizado por comprometimento do raciocínio, da realização de tarefas complexas e do julgamento, com sintomas tais como: compreensão pobre de situações de risco, redução da capacidade para cuidar das finanças, de tomar decisões e de planejar atividades complexas ou sequenciais;

- habilidades visuais-espaciais, com sintomas que incluem: incapacidade de reconhecer faces ou objetos comuns, encontrar objetos no campo visual, dificuldade para manusear utensílios, para vestir-se, não explicáveis por deficiência visual ou motora;

- linguagem (expressão, compreensão, leitura e escrita), com sintomas que incluem: dificuldade para encontrar e/ou compreender palavras, erros ao falar e escrever, com trocas de palavras ou fonemas, não explicáveis por déficit sensorial ou motor; 
- personalidade ou comportamento, com sintomas que incluem alterações do humor (labilidade, flutuações atípicas), agitação, apatia, desinteresse, isolamento social, perda de empatia, desinibição, comportamentos obsessivos, compulsivos ou socialmente inaceitáveis ${ }^{28}$.

O programa de ação em saúde mental da Organização Mundial da Saúde incluiu as demências como um grupo de doenças que merecem atenção prioritária. A reunião da Assembleia Geral das Nações Unidas, em 2011, sobre prevenção e controle de doenças não comunicáveis, adotou uma declaração política que diz: o ônus global e a ameaça das doenças não comunicáveis constituem um dos maiores desafios do desenvolvimento no século XXI, e apontou que doenças mentais e neurológicas, incluindo a doença de Alzheimer, são importante causa de morbidade e contribuem para o ônus global das doenças não comunicáveis ${ }^{29,30}$.

Habitualmente, a doença de Alzheimer é de evolução lenta e pode afetar o indivíduo de diferentes maneiras. $O$ padrão mais comum de sintomas começa de forma insidiosa, com a piora gradual da memória, acompanhada de dificuldades na apreensão de novas informações e perda da habilidade de realizar tarefas da vida diária. À medida que a doença evolui, a deterioração é progressiva e as pessoas experimentam dificuldades no gerenciamento da sua vida, o que as torna dependentes de ajuda para a realização de simples tarefas do dia a dia. Na fase avançada, além do comprometimento da memória remota, ocorre a necessidade de supervisão para atividades básicas como tomar banho, se vestir, ir ao banheiro, comer e outros afazeres da vida diária, além de alterações comportamentais como irritabilidade, agressividade e alucinações. Na fase final da doença a pessoa perde a capacidade de se comunicar, deixa de reconhecer seus familiares e amigos, fica restrita ao leito e dependente de cuidados permanentes em horário integral ${ }^{31}$.

Tão significativa epidemiologicamente, a doença de Alzheimer, com o seu caráter crônico, incapacitante e evolutivo, de curso prolongado até a dependência total, provoca impacto considerável nas esferas familiar, social, econômica e política, como problema de saúde pública. O dano cerebral, no curso inexorável de aniquilamento da mente, instaura uma situação na qual os valores passam a ser questionados ${ }^{32}$. Talvez a aproximação do problema da demência possa iniciar-se com a interpelação que Kosik apresenta, ao discorrer sobre a práxis: quem é o homem, o que é a sociedade humano-social e como é criada esta sociedade? ${ }^{33}$
Autonomia pressupõe o princípio lapidar da liberdade de escolha ${ }^{34}$. Se não há condições do exercício desta liberdade, estamos nas encruzilhadas bioéticas que nos detêm, desafiadoramente, numa instigante indagação ética sobre o que é humano. Nessas circunstâncias, o que fazer para alcançar a realização das vontades, das determinações de tudo aquilo que é direito inalienável da pessoa demenciada? $\mathrm{Na}$ angústia dessas indagações, vislumbra-se a dimensão protetora da bioética ${ }^{35}$ direcionada a tudo o que possa representar perigo e indignidade para o idoso com capacidade de autonomia comprometida. Proteção que é responsabilidade dos familiares que dele cuidam e dos profissionais que o assistem. A proteção conflui para o sentido já consolidado dos conceitos da abordagem principialista: beneficência, não maleficência, justiça e, especialmente, a coroação da autonomia, perdida para sempre na devastação da doença de Alzheimer ${ }^{34,36}$.

O desafio é incomensurável. À anulação da autonomia e da via régia da comunicação verbal centrada na percepção do mundo, profissionais e familiares têm, agora, diante de si a provocação da procura de formas de cuidado ao idoso com doença de Alzheimer que impliquem em reconstruir a liberdade de escolhas que era dele, agora incapaz de exercer o seu poder de decisão.

Nessa reflexão apresentamos um fragmento do pronunciamento de Oliveira sobre o documentário Clarita, de Thereza Jessuroun ${ }^{37}$ : Não conseguiremos entender uma existência que vai dramaticamente silenciando a não ser em profundo silêncio de meditação. É assim que se torna possível acompanhar a caminhada de Clarita ao fundo de seu próprio poço e participar de sua solidão. Afinal, cada um de nós tem também o seu próprio fundo do poço, que esconde lá dentro segredos, histórias e as próprias raízes de nossa liberdade. Um fundo que também mistura lá dentro, em estado de dramática fusão, passado, presente e projetos de futuro. Um passado que é a sacralização de todas as lembranças; um presente que é a consumação efêmera da atenção e um futuro que deixa de ser esperança para ser a própria dignificação da espera ${ }^{38}$.

\section{Considerações finais}

A capacidade de autodeterminação, tão valorizada na sociedade contemporânea, se esvai na pessoa com doença de Alzheimer. Na impossibilidade de exercer seu inalienável direito de autonomia, aqueles que cuidam assumem a responsabilidade de o fa- 
zer por ele - buscando ao máximo preservar sua individualidade e, assim, fazendo do cuidado a obra e a arte humana de prosseguir a construção do outro.

Buscamos, incansavelmente, a felicidade de viver com dignidade e não apenas sobreviver. Fazemos de tudo para combater a doença, a dor, o sofrimento e vencer a própria morte. Estamos cada vez mais aparelhados com fantásticas inovações tecnológicas para essa empreitada e são previstas transformações ainda mais profundas para este milênio. Num momento de 'ilusão utópica' chegamos até a acreditar que a realidade da perda das nossas capacidades, da doença incurável e da morte não fazem parte da existência. Pensamos e agimos como se fôssemos imortais, imunes às adversidades das doenças incapacitantes.

A reflexão bioética na sua essência é um grito pelo resgate da dignidade de vida humana, ao nascer, crescer, desenvolver-se, atingir a maturidade, envelhecer; é um clamor pelas responsabilidades compartilhadas e pautadas no autorrespeito e respeito ao outro; é uma ânsia de cuidado na trama das inter-relações que nos colocam irmanados e inter- dependentes até o momento final para, então, dignamente, finalizar a vida.

Nasce, então, uma sabedoria a partir da reflexão, aceitação e assimilação do cuidado da vida humana, do acolhimento ao idoso com doença de Alzheimer que chegou à dependência total até o final da vida. É um desafio aprender a cuidar e proteger o idoso com demência sem exigir retorno, com a gratuidade com que se ama e protege um bebê, num contexto social em que tudo é medido pelo mérito. Diante dessa situação desafiadora somos levados a buscar recursos para além da formação acadêmica, lá onde somos habitados pela sensibilidade, pela capacidade de cuidar e pela disposição de proteger.

A geriatria e a gerontologia estão convocadas a responder a esse desafio, sustentadas pelos referenciais da bioética. Não há soluções imediatas. Há, sim, um desafiante percurso frente à necessidade urgente de oferecer aos profissionais e à sociedade indicações de caminhos éticos que potencializem a integração do idoso com doença de Alzheimer à essência do cuidado humanizado.

\section{Referências}

1. Potter VR. Bioethics: the science of survival. Persp Biol Med. 1970;14:27-153.

2. Potter VR. Bioethics: bridge to the future. New Jersey: Prentice-Hall; 1971. p. 9.

3. Freitas EV, Py L, editores. Tratado de geriatria e gerontologia. Rio de Janeiro: Guanabara-Koogan; 2011. p. 107-16.

4. Reich WT. Encyclopedia of bioethics. New York: Macmillan; 1978.

5. Reich WT. Encyclopedia of bioethics. $2^{\text {nd }}$ ed. New York: Macmillan; 1995.

6. Reich WT. The word 'bioethics': its birth and the legacies of those who shaped it. Kennedy Inst Ethics J. 1994;4:319-35.

7. Reich WT. Op. cit. p. 1994. 19-34.

8. Potter VR. Bioética global e sobrevivência humana. In: Pessini L, Barchifontaine CP. Problemas atuais de bioética. $5^{\text {a }}$ ed. São Paulo: Loyola; 2001. p. 343.

9. Potter VR. Op. cit. 1971. p. 346-7.

10. Post SG. Encyclopedia of bioethics. $3^{\mathrm{a}}$ ed. New York: Macmillan; 2003.

11. Alzheimer's Association. Alzheimer's disease facts and figures. Alzheimers Dement. 2013;9(2):20845.

12. Jeckel-Neto EA, Cunha GL. Teorias biológicas do envelhecimento. In: Freitas EV, Py L, editores. Tratado de geriatria e gerontologia. Rio de Janeiro: Guanabara-Koogan; 2006. p.13-22.

13. Doll J, Py L. O idoso na relação com a morte: aspectos éticos. In: Neri AL, organizador. Qualidade de vida na velhice: enfoque multidisciplinar. Campinas: Alínea; 2007. p. 279-300.

14. Jacques E. Morte e crise da meia-idade. Int J Psychoanal. 1965;(46):502-14.

15. Torres WC. Morte e desenvolvimento humano. In: PY L, organizadora. Finitude: uma proposta para reflexão e prática em gerontologia. Rio de Janeiro: Nau; 1999. p. 55-63.

16. Cicerón MT. De senectude. Madrid: Triacastela; 2001.

17. Camarano AA, Kanso S. Envelhecimento da população brasileira: uma contribuição demográfica. In: Freitas EV, Py L, editores. Op. cit. p. 58-73.

18. Schotsmans P. A vida como plenitude: contribuição dos idosos para uma civilização digna do homem. O Mundo da Saúde. 1999;23(4):245-51.

19. Kastembaum R. Velhice: anos de plenitude. São Paulo: Harper \& Row do Brasil; 1981.

20. Foucalt M. O nascimento da clínica. Rio de Janeiro: Forense Universitária; 1998.

21. Frankl VE. Em busca de sentido: um psicólogo no campo de concentração. Petrópolis: Vozes; 1991.

22. Machado JCB. Doença de Alzheimer. In: Freitas EV, Py L, editores. Op. cit. p. 178-201. 
23. World Health Organization. Dementia: a public health priority. Geneva: WHO; 2012. Disponível: http://apps.who.int/iris/bitstream/10665/75263/1/9789241564458_eng.pdf?ua=1

24. Jack CR Jr, Albert MS, Knopman DS, McKhann GM, Sperling RA, Carrillo MC et al. Introduction to the recommendations from the National Institute on Aging-Alzheimer's Association workgroups on diagnostic guidelines for Alzheimer's disease. Alzheimers Dement. 2011;7(3):257-62.

25. McKhann GM, Knopman DS, Chertkow H, Hyman BT, Jack CR Jr, Kawas CH et al. The diagnosis of dementia due to Alzheimer's disease: recommendations from the National Institute on AgingAlzheimer's Association workgroups on diagnostic guidelines for Alzheimer's disease. Alzheimers Dement. 2011;7(3):263-9.

26. Albert MS, DeKosky ST, Dickson D, Dubois B, Feldman HH, Fox NC et al. The diagnosis of mild cognitive impairment due to Alzheimer's disease: recommendations from the National Institute on Aging-Alzheimer's Association workgroups on diagnostic guidelines for Alzheimer's disease. Alzheimers Dement. 2011;7(3):270-9.

27. Sperling RA, Aisen PS, Beckett LA, Bennett DA, Craft S, Fagan AM et al. Toward defining the preclinical stages of Alzheimer's disease: recommendations from the National Institute on AgingAlzheimer's Association workgroups on diagnostic guidelines for Alzheimer's disease. Alzheimers Dement. 2011;7(3):280-92.

28. Frota NAF, Nitrini $R$, Damasceno BP, Forlenza $O$, Silva $A B$, Magaldi RM et al. Critérios para o diagnóstico de doença de Alzheimer. Dement neuropsychol. 2011;5(1 Suppl):5-10.

29. Mental Health Gap Action Programme. Intervention guide for mental, neurological and substance use disorders in non-specialized health settings. Geneva: WHO; 2010.

30. Mental Health Gap Action Programme. Evidence Resource Centre. [Internet]. Geneva: WHO; 2012 (acesso 17 mar. 2014). Disponível: http://www.who.int/mental_health/mhgap/evidence/ en/index.html

31. Alzheimer's Disease International. World Alzheimer's report 2010: the global economic impact of dementia. London: Alzheimer's Disease International; 2010.

32. Py L, Barbosa CRM, Teixeira MB. Demência: uma aproximação psicológica. In: Goldman SN, Paz SF, organizadores. Cabelos de neon. Niterói: Talento Brasileiro; 2001. p. 96-120.

33. Kosik K. Dialética do concreto. $2^{2}$ ed. Rio de Janeiro: Paz e Terra; 1976.

34. Nunes R, Melo HP. Testamento vital. Coimbra: Almedina; 2011. p. 87.

35. Ribeiro CDM, Schramm FR. A necessária frugalidade dos idosos. Cad Saúde Pública. 2004;20(5):1.141-8.

36. Pessini L, Barchifontaine CP. Bioética e longevidade humana. São Paulo: Loyola; 2006.

37. Jessouroun T. Samba. 2007. [Documentário com moradores da Mangueira].

38. Oliveira JFP. Clarita: tempo e memória. [Internet]. Portal do Envelhecimento. 2007. Disponível: http://www.portaldoenvelhecimento.org.br/psico/psico91.htm

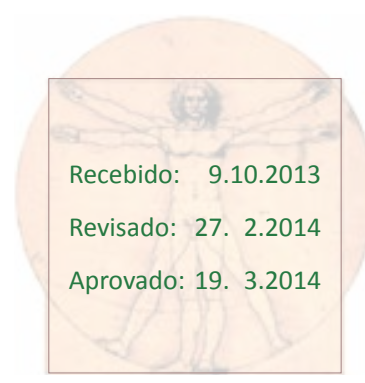

\section{Participação dos autores}

Todos os autores contribuíram na concepção do artigo e no desenvolvimento das ideias. 